\title{
Spatial distribution of Brevicoryne brassicae (L.) in Cabbage in mid-hills of Himachal Pradesh, India
}

\author{
S. C. Verma*, P. L. Sharma and R. K. Bhardwaj ${ }^{* *}$ \\ Department of Entomology, Dr YS Parmar University of Horticulture and Forestry, Nauni, Solan (Himachal \\ Pradesh), INDIA \\ **Department of Vegetable Science, Dr YS Parmar University of Horticulture and Forestry, Nauni, Solan \\ (Himachal Pradesh), INDIA \\ *Corresponding author. E-mail: scvermaento@gmail.com
}

Received: December 18, 2016; Revised received: March 11, 2017; Accepted: August 5, 2017

\begin{abstract}
Investigations were carried out during two consecutive Rabi seasons of 2014 and2015 at the Experimental Farm of the Department of Seed Science and Technology, Dr Y S Parmar University of Horticulture and Forestry, Nauni, Solan, Himachal Pradesh, India to study the spatial distribution of Brevicoryne brassicae in cabbage. One month old cabbage seedlings were planted in the field in the month of November during both the years. Distribution pattern of any insect population is an important aspect as it represents the interaction between individuals of the species and their habitat. Spatial distribution is useful for designing efficient sampling programmes for population estimation and development of population models. Spatial distribution is also important to understand the bioecology of the pest and to determine the sampling protocol for that species. In the present study variance to mean ratio ( $\mathrm{s}^{2} /$ $\mathrm{X}$ ), mean crowding $\left(\mathrm{X}^{*}\right)$, ratio of mean crowding to mean $\left(\mathrm{X}^{*} / \mathrm{X}\right)$, ' $\mathrm{k}$ ' of negative binomial, Taylor's power equation $\left(\mathrm{s}^{2}=\right.$ $0.9099 X^{1.55}$ during 2014 and $s^{2}=2.9861 X^{1.1949}$ during 2015), Iwao's patchiness regression and optimum number of samples $\left(\mathrm{N}_{\mathrm{opt}}\right)$ required to achieve the desired precision were calculated for different densities. Cabbage aphid, $B$. brassicae appeared in the fourth standard week i.e last week of January( 26.2 aphids/ plant during 2014 and 0.30 aphids/ plant during 2015) and persisted upto thirteenth standard week i.e last week of April ( 18.4 aphids/ plant during 2014 and 18.2 aphids/ plant during 2015) and followed a negative binomial distribution during both years. Optimum number of samples $\left(\mathrm{N}_{\mathrm{opt}}\right)$ required varied with mean density as well as precision level. The present study will serve as basic information to develop a sampling plan of $B$. Brassicae in cabbage for its monitoring and management.
\end{abstract}

Keywords: Brevicoryne brassicae, Cabbage aphid, Cole crops, Dispersion, Sampling

\section{INTRODUCTION}

Cabbage (Brassica oleracea var. Capitata L.) is an important cash crop of Himachal Pradesh grown for culinary purpose and also for seed production. It is mostly grown in winter, but, in the mountainous region of the country, cabbage is also grown during summer months. Cabbage aphid, Brevicoryne brassicae (L.) is a serious pest of cabbage in Himachal Pradesh particularly during winter season (Bhalla and Verma, 1991; Sharma and Sharma, 1999; Theunjssen, 1989; Verma et al., 2008). It is a pest of economic importance as it arrests crop growth seriously and has a tendency to contaminate the crop rendering it unattractive. It has been reported that cabbage aphid, B. brassicae caused 2 to 84 per cent damage to the cabbage crop (Prasad, 1963). The aphids prevented 62 per cent plants from forming marketable heads in the natural population. Distribution pattern of an insect population is an important aspect as it represents the interaction between individuals of the species and their habitat. The biological cause of aggregation is largely behavioural, but, ISSN : 0974-9411 (Print), 2231-5209 (Online) All Rights Reserved $\odot$ Applied and Natural Science Foundation www.jans.ansfoundation.org highly unpredictable (Lloyd,1967). Therefore, knowledge of spatial distribution is useful for designing efficient sampling programmes for population estimation, pest management and development of population models and assessment of levels of damage. Many workers have studied in this direction by recording actual number of aphids on randomly selected plants (Anscombe, 1949; Rhainds and Messing, 2005; Chander and Phadke, 1994). Knowledge of an insect's distribution pattern provides an informative description of a population (Iwao, 1968). The required number of samples vary with pest density and spatial distribution of the pest. Type of spatial distribution can therefore affect the sampling programme and the method of analysis of the data (Southwood and Henderson, 2000). The knowledge of spatial distribution is also important to understand the bioecology of the pest and to determine the sampling protocol for that species. Seasonal population fluctuation of $B$. brassicae has been studied (Verma et al., 2008) but the information on spatial distribution is lacking. Therefore, the aim of the 
present study was to develop a sampling procedure suitable for population dynamics studies of the cabbage aphid , B. brassicae on cabbage to determine the within- and between-plant distributions and temporal changes in spatial pattern of the aphid in cabbage fields.

\section{MATERIALS AND METHODS}

The present study was conducted during two consecutive Rabi seasons of 2014-15 and2015-16 at the Experimental Farm of the Department of Seed Science and Technology of Dr Y S Parmar University of Horticulture and Forestry, Nauni, Solan, Himachal Pradesh. One month old cabbage seedlings (cv. Bharti) were planted in the field in the month of November during both the years. The crop was raised by following all the recommended agronomic practices (Annonymous,2009). The aphid population was recorded as per method of Sachan and Srivastava (1972). Population of B. brassicae was recorded after 15 days of transplanting at weekly intervals on 3- leaf sample, one each from lower, middle and upper whorl from each plant and mean aphid population was counted.

\section{Data analysis:}

Indices of spatial distribution or dispersion: Variance to mean ratio is the simplest approach to measure dispersion and for this mean population density (X) and variance $\left(\mathrm{s}^{2}\right)$ of the aphid was calculated for each sampling date using standard statistical procedure. The ratio between variance and mean density was calculated by dividing variance by the mean $\left(\mathrm{s}^{2} / \mathrm{X}\right)$. This ratio is one for poison or random distribution, less than one for uniform distribution and more than one for aggregated or negative binomial distribution. A null hypothesis that the aphid follows poison distribution was considered and the departure of the distribution from random to uniform or aggregated was tested by calculating the index of distribution $\left(\mathrm{I}_{\mathrm{D}}\right)$ which was further used to calculate $\mathrm{z}$ values as

$\mathrm{I}_{\mathrm{D}}=\left(\mathrm{s}^{2} / \mathrm{X}\right)(\mathrm{n}-1) \ldots . .(1)$

where $\mathrm{s}^{2}=$ variance, $\mathrm{X}=$ mean, $\mathrm{n}=$ number of samples, $\mathrm{Z}=\mathrm{v} 2 \mathrm{ID}-\mathrm{v} 2 \mathrm{v}-1 \ldots \ldots .(2)$,

where $\mathrm{v}=\mathrm{n}-1$

Z- value between -1.96 and +1.96 confirms the random distribution, whereas,z-value less than-1.96 and more than +1.96 verifies uniform and aggregated distribution, respectively( Patil and Stiteler, 1974). The index of clumping or David -Moore index (IDM) was calculated as per David and Moore ( David and Moore, 1954):

IDM $=\mathrm{s}^{2} / \mathrm{X}-1 \ldots \ldots(3)$

$\mathrm{s}^{2}=$ variance and $\mathrm{X}=$ mean.

The value of IDM is zero for random distribution, less than zero for uniform and more than one for aggregated distribution. Mean crowding $\left(\mathrm{X}^{*}\right)$ which explains the possible effect of competition and mutual interference among individuals was calculated as: $\mathrm{X}^{*}=\mathrm{X}+$ IDM.--------(4)

Lloyd's mean crowding crowding index $\left(\mathrm{X}^{*} / \mathrm{X}\right)$ was also worked to verify the type of distribution ( Lloyd,1967). The value of $\left(\mathrm{X}^{*} / \mathrm{X}\right)$ is $1,<1$ and $>1$ for random, uniform and aggregated distribution, respectively. The ' $\mathrm{k}$ ' of negative binomial, often referred to as the parameter of dispersion, was calculated as under (Southwood and Henderson,2000): $\mathrm{k}=\mathrm{X}^{2} /\left(\mathrm{s}^{2}-\mathrm{X}\right)$---------(5).

The relationship between variance and mean was worked out by fitting Taylor's power equation as $\mathrm{s}^{2}=$ $\mathrm{aX}{ }^{\mathrm{b}} \ldots \ldots . . .(6)$ or

$\operatorname{logs}{ }^{2}=\log \mathrm{a}+\mathrm{b} \log \mathrm{X}------(7)$

Where, $a=$ sampling parameter, $b=$ index of aggregation. The Iwao's patchiness regression (Iwao, 1972) between mean crowding and mean density was calculated as under:

\section{$\mathrm{X}^{*}=\mathrm{a}+\mathrm{bX}--------(8)$}

where, brefers to the coefficient of contiguousness. The distribution with $\mathrm{a}=0$ and $\mathrm{b}=>1$ corresponds to aggregated distribution and $a=0$ and $b=1$ to random distribution, whereas $\mathrm{a}=0$ and $\mathrm{b}=<1$ corresponds to uniform distribution.

Optimum number of samples: The optimum number of samples $\left(\mathrm{N}_{\mathrm{opt}}\right)$ required to achieve the desired precision (desired standard error of mean) was calculated for different densities. Generally, a precision level (expressed as standard error of mean) of about $25 \%$ is desired, however, if the estimate is required to construct the life table a higher level of precision $(10 \%)$ is desirable (Southwood and Henderson, 2000 ). Hence, the $\mathrm{N}_{\text {opt }}$ was calculated for different densities at 10, 20 and $30 \%$ standard error by using the following formula:

$\mathrm{N}_{\text {opt }}=(\mathrm{t} / \mathrm{D})^{2}$ a $\mathrm{X}^{\mathrm{b}-1}$

where, $t$ is the tabulated value of student's at $p=0.05$, $\mathrm{D}$ is the desired precision/ standard error, $\mathrm{X}$ is the mean density and a and $\mathrm{b}$ are Taylor's regression coefficients.

\section{RESULTS AND DISCUSSION}

Seasonal host plant interaction of $\boldsymbol{B}$. brassicae: Data presented in Table 1 reveal that the first incidence of cabbage aphid appeared on the cabbage plants during the fourth standard week i.e last week January, 2014 with an average density of 26.2 aphids per plant and persisted throughout the cropping season with two peaks, first (32.5 aphids/ plant) during the fifth standard week i.e. first week February,2014 and second (39.3 aphids/plant) during the tweleveth standard week i.e. last week of March. During 2015, the aphid incidence occurred (0.30 aphids/plant) during the fourth standard week i.e. last week of January and persisted upto thirteenth standard week i.e April with two peaks first on ninth standard week i.e Ist week of March(20.9 aphids/plant) and tweleveth 
S. C. Verma et al. / J. Appl. \& Nat. Sci. 9 (3): 1587 -1591 (2017)

Table 1: Spatial distribution of B. brassicae on cabbage under mid-hill conditions during 2014.

\begin{tabular}{|c|c|c|c|c|c|c|c|c|}
\hline \multirow{2}{*}{$\begin{array}{l}\text { Standard } \\
\text { week }\end{array}$} & \multicolumn{8}{|c|}{ Population density and indices of dispersion } \\
\hline & $\mathbf{X}$ & $\sigma^{2}$ & $\sigma^{2} / \mathbf{X}$ & $\mathbf{k}$ & $\mathbf{Z}$ & IDM & $\mathbf{X}^{*}$ & $\mathbf{X} * / \mathbf{X}$ \\
\hline IV & 26.2 & 298.6 & 11.4 & 25.1 & 10.2 & $\begin{array}{l}10.4 \\
\end{array}$ & 36.6 & $\begin{array}{l}1.4 \\
\end{array}$ \\
\hline V & 32.8 & 90.0 & 2.7 & 18.8 & 2.9 & 1.7 & 34.5 & 1.1 \\
\hline VI & 12.3 & 60.5 & 4.9 & 3.1 & 5.3 & 3.9 & 16.2 & 1.3 \\
\hline VII & 8.6 & 40.9 & 4.8 & 2.3 & 5.2 & 3.8 & 12.4 & 1.4 \\
\hline VIII & 14.1 & 32.1 & 2.3 & 12.2 & 2.3 & 1.3 & 15.4 & 1.1 \\
\hline IX & 11.8 & 30.0 & 2.5 & 7.7 & 2.6 & 1.4 & 13.2 & 1.1 \\
\hline $\mathrm{X}$ & 8.5 & 24.7 & 2.9 & 4.5 & 3.1 & 1.9 & 10.4 & 1.2 \\
\hline XI & 13.2 & 31.7 & 2.4 & 9.4 & 2.5 & 1.4 & 14.6 & 1.1 \\
\hline XII & 39.3 & 370.9 & 9.4 & 4.7 & 8.9 & 8.4 & 47.7 & 1.2 \\
\hline XIII & 18.4 & 116.0 & 6.3 & 3.5 & 6.5 & 5.3 & 23.7 & 1.3 \\
\hline $\begin{array}{c}\text { Taylor's } \\
\text { power } \\
\text { equation }\end{array}$ & \multicolumn{8}{|c|}{$\sigma^{2}=0.9099 \mathrm{X}^{1.55}\left(\mathrm{r}^{2}=0.7271\right)$} \\
\hline $\begin{array}{l}\text { Iwao's } \\
\text { regression }\end{array}$ & \multicolumn{8}{|c|}{$\mathrm{X}^{*}=0.7983+1.1702 \mathrm{X}\left(\mathrm{r}^{2}=0.9571\right.$} \\
\hline
\end{tabular}

$\mathrm{X}$-mean density, $\sigma^{2}$ - variance, $\mathrm{k}$ - parameter of dispersion, $\mathrm{z}-\mathrm{z}$ value, IDM -David More index, $\mathrm{X}^{*}$ - mean crowding

standard week i.e. last week of March(25.2 aphids/ plant). The present findings corroborate the findings of Verma et al.(2008). who reported that cabbage aphid population persisted throughout the cropping period and maximum population was observed in $3^{\text {rd }}$ week of January,2004-05 and $3^{\text {rd }}$ week of February,2005-06.

Spatial distribution of $\boldsymbol{B}$. brassicae: It is extrapolated from Tables 1 and 2 that variance was higher than mean density which indicated aggregated or negative binomial distribution for the aphids at all sampling dates during both the years. The mean variance ratio is the simplest and most fundamental indices for determination of aggregation. The variance to the mean ratio $\left(\mathrm{s}^{2} / \mathrm{X}\right)$ during the both years was more than one, which showed a negative binomial distribution of the aphid. This ratio varied between 2.3 to 11.4 during 2014 and 2.2 to 9.1 during 2015 for different standard weeks. The index of dispersion $I_{D}$ and z-values were calculated to know the departure of the distribution from randomness to poison. The results of Z-values during both the years showed variation from 2.3 to 10.2 during 2014 and 2.2 to 8.7 during 2015 for different standard weeks. In this study, all these values were more than 1.96 which confirmed aggregated or negative binomial spatial distribution andthe null hypothesis for poison distribution was rejected. The David More Index(IDM) also confirmed the negative binomial distribution of the aphid. The Lloyd's mean crowding ( $\mathrm{X}^{*}$ ) varied from 10.4 to 47.7 and 2.3 to 31.4 during 2014 and 2015, respectively, for different standard weeks. The mean crowding to mean ratio $\left(X^{*} / \mathrm{X}\right)$ fluctuated between 1.1 to 1.4 during 2014 and 1.1 to 7.7 during 2015.The maximum value of mean ratio $\left(\mathrm{X}^{*} / \mathrm{X}\right)$ was found equal on $\mathrm{IV}$ and VII standard week (both 1.4) of crop season of 2014 and
IV standard week ( 7.7) of crop season of 2015 which again verified the aggregated nature of the spatial distribution of the aphid. Taylor's power equation and patchiness regression were fitted to study the relationship between variance and mean, and between mean crowding and mean, respectively. The patchiness regression fitted to the negative binomial was $\mathrm{X}^{*}=0.7983+1.1702 \mathrm{X}\left(\mathrm{r}^{2}=0.9571\right)$ and $\mathrm{X}^{*}=$ $2.2975+1.1301 X\left(r^{2}=0.9567\right)$ during 2014 and 2015, respectively and Taylor power equation was $\mathrm{s}^{2}=$ $0.9099 \mathrm{X}^{1.55}\left(\mathrm{r}^{2}=0.7271\right)$ and $\mathrm{s}^{2}=2.9861 \mathrm{X}^{1.1949}\left(\mathrm{r}^{2}=\right.$ 0.9485 ) during the respective years confirming the strong contiguous and dependence of variance on mean density. The present findings corroborate the findings of Singh et al. (2016). who also reported that the Lloyd's mean crowding $\left(\mathrm{X}^{*}\right)$ varied from 11.9 to 140.8 and 15 to 89 during 2013 and 2014, respectively, for different sampling dates. The mean crowding to mean ratio $\left(\mathrm{X}^{*} / \mathrm{X}\right)$ ranged from 1.03 to 1.11 during 2013 and from 1.05 to 1.45 during 2014 which again verified the aggregated nature of the spatial distribution of the aphid. The contiaguous distribution of aphid has also been reported by Rai and Singh (1993) on Brassica crops and Devi (1998) on Cole crops. The value of dispersion parameter ' $\mathrm{k}$ ' was calculated for each sample. It fluctuated from 2.3 to 25.1 during 2014 and 0.15 to 8.32 during 2015 . The maximum value of ' $\mathrm{k}$ ' was found in the fourth standard week i.e. last week of January, 2014 and thirteenth standard week i.e. first week of April, 2015. Akhtar et al. (2010) reported that the value of dispersion parameter ' $\mathrm{k}$ ' of mustard aphid, Lipaphis erysimi was fluctuated between 1.41 and 6.13 during 2006-07 and 2.72 and 8.80 during 2007-08. The parameter ' $\mathrm{k}$ ' is a general reciprocal index of dispersion that also arises as the 
Table 2: Spatial distribution of B. brassicae on cabbage under mid-hill conditions during 2015.

\begin{tabular}{|c|c|c|c|c|c|c|c|c|}
\hline \multirow{2}{*}{$\begin{array}{l}\text { Standard } \\
\text { week }\end{array}$} & \multicolumn{8}{|c|}{ Population density and indices of dispersion } \\
\hline & $\mathbf{X}$ & $\sigma^{2}$ & $\sigma^{2} / \mathbf{X}$ & $\mathbf{k}$ & $\mathbf{z}$ & IDM & $\mathbf{X}^{*}$ & $\mathbf{X} * \mathbf{X}$ \\
\hline IV & 0.3 & 0.9 & 3.0 & 0.15 & 3.2 & 2.0 & 2.3 & 7.7 \\
\hline $\mathrm{V}$ & 2.5 & 5.4 & 2.2 & 2.2 & 2.2 & 1.2 & 3.7 & 1.5 \\
\hline VI & 12.2 & 57.3 & 4.7 & 3.3 & 5.1 & 3.7 & 15.9 & 1.3 \\
\hline VII & 5.5 & 16.9 & 3.1 & 2.7 & 3.3 & 2.1 & 7.6 & 1.4 \\
\hline VIII & 10.5 & 95.8 & 9.1 & 1.3 & 8.7 & 8.1 & 18.6 & 1.8 \\
\hline IX & 20.9 & 103.2 & 4.9 & 5.3 & 5.3 & 3.9 & 24.8 & 1.2 \\
\hline $\mathrm{X}$ & 12.7 & 83.3 & 6.6 & 2.3 & 6.8 & 5.6 & 18.3 & 1.4 \\
\hline XI & 15.2 & 76.0 & 5.0 & 3.8 & 5.4 & 4.0 & 19.2 & 1.3 \\
\hline XII & 25.2 & 182.4 & 7.2 & 4.3 & 7.3 & 6.2 & 31.4 & 1.2 \\
\hline XIII & 18.2 & 58.0 & 3.2 & 8.32 & 3.5 & 2.2 & 20.4 & 1.1 \\
\hline $\begin{array}{l}\text { Taylor's } \\
\text { power } \\
\text { equation } \\
\end{array}$ & \multicolumn{8}{|c|}{$\sigma^{2}=2.9861 X^{1.1949}\left(r^{2}=0.9485\right)$} \\
\hline $\begin{array}{l}\text { Iwao's } \\
\text { regression }\end{array}$ & \multicolumn{8}{|c|}{$\mathrm{X}^{*}=2.2975+1.1301 \mathrm{X}\left(\mathrm{r}^{2}=0.9567\right.$} \\
\hline
\end{tabular}

$\mathrm{X}$-mean density, $\sigma^{2}$ - variance, $\mathrm{k}$ - parameter of dispersion, $\mathrm{z}-\mathrm{z}$ value, IDM -David More index, $\mathrm{X}^{*}$ - mean crowding

Table 3. Optimum number of samples of B. brassicae at different densities and precisions.

\begin{tabular}{|c|c|c|c|c|c|c|}
\hline \multirow[t]{4}{*}{ Density( X ) } & \multicolumn{6}{|c|}{ Year } \\
\hline & \multicolumn{3}{|c|}{2014} & \multicolumn{3}{|c|}{2015} \\
\hline & \multicolumn{6}{|c|}{ Precision(D) } \\
\hline & 0.1 & 0.2 & 0.3 & 0.1 & 0.2 & 0.3 \\
\hline 5 & 193.2 & 48.3 & 21.5 & 355.2 & 88.9 & 39.5 \\
\hline 10 & 141.4 & 35.5 & 15.8 & 202.6 & 50.6 & 22.5 \\
\hline 20 & 103.5 & 25.9 & 11.5 & 115.5 & 28.9 & 12.8 \\
\hline 50 & 68.5 & 17.1 & 7.6 & 55.0 & 13.8 & 6.1 \\
\hline 100 & 50.2 & 12.5 & 5.6 & 31.4 & 7.8 & 3.5 \\
\hline
\end{tabular}

parameter of negative binomial. Arbab and Mirphakhar (2016) reported that Taylor's $b$ and Iwao's $\square$ $\square$ were both significantly more than 1 , indicating that adults and larvae of Bactrocera oleae in olive orchards had aggregated spatial distribution. Jimenez Pino et al.( 2011) reported that density of maps for Cydia fagiglandana showed an heterogenous and aggregated distribution and spatio-temporal stability in holm oak ( Quercus ilex L. ) forest.

Optimum number of samples: Data contained in Table 3 reveal that the optimum number of samples required varied with the mean density and the precision level desired for the aphid. At low densities, large sample size and at high densities small sample size are required for achieving same precision level. It can therefore be concluded that during the beginning and towards the end of the season when the mean densities of the aphid are low, more number of samples are required to achieve the desired precision of the estimate. Whereas, in the middle of the season, when densities of the aphid are high, even less number of samples will achieve the same level of precision. Similar results have been reported by Moradi-Vajargah et al. (2011) for alfalfa weevil , Hypera postica (Gyllenhal) at 15, 20 and 30 per cent level of precisions and further observed that to acquire higher level of precision, the 15 per cent level could be adopted whereas in IPM programmes 20 per cent level would be acceptable. Singh et al. (2016) for Eriosoma lanigerum and Aphilinus mali on apple observed that in the beginning and towards end when of the season when the mean densities of both the aphid and the parasitoid are low, more number of samples are required to achieve the desired precision of the estimate, whereas, in the middle of the season when the densities of the aphid and its parasitoid are high even less number of samples will achieve the same level of precision in India.

\section{Conclusion}

The variance to the mean ratio of cabbage aphid and $B$. brassicae during the both years was more than one, which showed a negative binomial distribution of the aphid. This ratio varied between 2.3 to 11.4 during 2014 and 2.2 to 9.1 during 2015 for different standard weeks. The optimum number of samples required varied with mean population density and it It is concluded that more number of samples is required at low densities and higher precision and vice versa for population estimation. This study will be helpful in 
developing sampling programmme for the cabbage aphid.

\section{ACKNOWLEDGEMENTS}

Authors are thankful to the Indian Council of Agricultural Research for providing funds through All India Co-ordinated Research Projects on Vegetable Crops and Professor and Head, Department of Seed Science and Technology for providing necessary facilities for conducting the research work. The authors do not have any conflict of interest.

\section{REFERENCES}

Akhtar, M.S., Dey, D., and Usmani, M.K .(2010) Spatial distribution of mustard aphid Lipaphiserysimi (Kaltenbach) vis-a- vis its parasitoid, Diaretiellarapae (M' intosh). World Applied Science Journal. 11(3): 284-288.

Annonymous. (2009) Package of practices of vegetable crops. Directorate of Extension Education. Dr Y S Parmar University of Horticulture and Forestry, Nauni, Solan-173230 HP.

Anscombe, F. J. (1949) The statistical analysis of insects counts based on negative binomial distribution. Biometrices , 5: 165-175.

Arbab, A., and Mirphakhar, F. (2011). Spatial distribution pattern and sequential sampling plans for Bactrocera oleae (Gmelin) (Dip: Tephritidae) in olive orchards. Journal of Entomological and Acarological Research, 48: 23-38 .

Bhalla, O.P. , Verma, A.K. (1991) Final Project Report, ICAR Adhoc Research Project'Integrated pest management studies on cauliflower and cabbage in temperate regions of Himachal Pradesh." Department of Entomology, Dr Y S Parmar university of Horticulture and Forestry, Solan, Himachal Pradesh, $50 \mathrm{p}$.

Chander, S., Phadke, K.G. (1994) Spatial distribution and transformation of aphid counts on Rapeseed. Shashpa 1: 21-28.

David, F.N., Moore, G.P.(1954) Notes on contagious distributions in plant populations. Annals of Botany, 18: 47-53.

Devi, P.B. (1998) Bioecology of Myzuspersicae (Sulzer) (Homoptera: Aphididae) on certain cole crops in Manipur, Ph.D. Thesis Manipur University.

Iwao, S.(1968) A New Regression Method for Analyzing the Aggregation Pattern of Animal Populations. Research on Population Ecology10: 1-20.
Iwao, S. (1972) Application of the m-m method to the analysis of spatial patterns by changing the quadrat size . Research on Population Ecology 14: 97-128.

Jimenez-Pino, A., Maistrello, L., Lopez-Martinez, M. A., Ocete-Rubio, M. E. and Soria-Iglesias, F. J. (2011). Spatial.distribution of Cydia fagiglandana (Zeller) in an exploited holm oak (Quercus ilex L.) forest. Spanish Journal of Agricultural Research, 9(2): 570-579.

Lloyd, M. (1967) Mean crowding. Journal of Animal Ecology. 36: 1-30.

Moradi-Vajargah, M., Golizadeh, A., Rafieedastjerdi, H., Zalucki, M.P., Hassanpour, M. and Patil, G.P. , Stiteler, W.M. (1974) Concepts of aggregation and their quantification : a critical review with some new results and applications. Research Population Ecology : 238-254.

Prasad, S.K. (1963). Quantitative estimation of damage to cruciferous crops caused by cabbage worm, cabbage looper,diamond back moth and cabbage aphid. Indian Journal of Entomology. 25 (3): 242-259.

Rai, S. and Singh, V.S.(1993). Spatial distribution of aphids infesting cabbage and cauliflower. Indian Journal of Entomology. 55: 178-183.

Rhainds,M., and Messing, R.H. ( 2005) Spatial and temporal density dependence in a population of melon aphid, Aphis gossypii Glover (Homoptera : Aphididae) on established and sentinel taro plants. Applied Entomology and Zoology.40:273-282.

Sachan, J.N., and Srivastava, B.P. (1972) Studies on the seasonal incidence of insect-pests of cabbage. Indian Journal of Entomology 4(2):123-29.

Sharma, K.C., Sharma, D. (1999) Insect-pests of exotic vegetables in Himachal Pradesh. Insect Environment. 5 (3):118-9.

Singh, J., Chandel, R.S., Sharma, P.L. (2016). Spatial distribution and interaction of Eriosomala nigerum and Aphelinusmali on apple under dry- temperate conditions of India. Proceedings of National Academy of Sciences Section B Biological Science. DOI 10.1007/s 40011016-0765-4

Southwood, T. R. E. , Henderson, P. A. (2000) Ecological Methods. 3rd Edition, Blackwell Science, UK, 575PP.

Theunjssen, N.(1989) Integrated control of aphids on field grown vegetables. In: Aphids their biology, natural enemies and control. Vol C. (eds. Ak Minks, P Harrewijn), pp 285-89.

Verma, S.C., Kanwar,H.S.,Joshi, A.K.(2008) Population buildup, cabbage aphid, Brevicoryne brassicae (L.) on cabbage in relation to weather factors. Himachal Journal of Agriculture Research. 34(2):47-49. 